\title{
Should the Same Products Consumed in Different Retail Channels Have an Identical Carbon Footprint? An Environmental Assessment of Consumer Preference of Retail Channels and Mode of Transport
}

\author{
Jenhung Wang ${ }^{1, *}$ and Pei-Chun Lin ${ }^{2}(\mathbb{D}$ \\ 1 Department of Logistics Management, National Kaohsiung University of Science and Technology, \\ Kaohsiung 824, Taiwan \\ 2 Department of Transportation and Communication Management Science, National Cheng Kung University, \\ Tainan 701, Taiwan; peichunl@mail.ncku.edu.tw \\ * Correspondence: jenhung@nkust.edu.tw; Tel.: +886-76011000-33217
}

check for updates

Citation: Wang, J.; Lin, P.-C. Should the Same Products Consumed in Different Retail Channels Have an Identical Carbon Footprint? An Environmental Assessment of Consumer Preference of Retail Channels and Mode of Transport. Sustainability 2021, 13, 615. https://doi.org/10.3390/su13020615

Received: 6 December 2020

Accepted: 7 January 2021

Published: 11 January 2021

Publisher's Note: MDPI stays neutral with regard to jurisdictional clai$\mathrm{ms}$ in published maps and institutional affiliations.

Copyright: $(\odot 2021$ by the authors. Licensee MDPI, Basel, Switzerland. This article is an open access article distributed under the terms and conditions of the Creative Commons Attribution (CC BY) license (https:// creativecommons.org/licenses/by/ $4.0 /)$.
Abstract: This study involved an environmental assessment of retail channels using the simplified life-cycle assessment (LCA) method to quantify the environmental impact of packaged beverages consumed in 7-Eleven convenience stores (c-stores) and Carrefour hypermarkets, with the aim of offering shoppers more environmentally friendly chain stores. The life-cycle impact assessment (LCIA) of packaged drinks at the point of sale (POS) shows the environmental impact of (1) consumer transportation mode and (2) truck distribution. A comparative analysis was conducted on the consumption of 1800 cartons of packaged beverages in c-stores compared to hypermarket channels replenished by individual distribution systems. The paired $t$-test was used to assess the impact of the consumption of 1800 boxes of 24 packs of 10-ounce drinks. The significance level of the beverages consumed in Carrefour and 7-Eleven c-stores differed by 0.1. The logistics-focused LCA explained the environmental and business rationale for replenishment and sustainable customer transportation. We conclude that, due to consumer preference for retail channels and mode of transport, the carbon footprint for the same products consumed in different channels should not be identical. The research demonstrated a tool to convey more environmental profiles of transportation mode selection to consumers and contribute to building sustainable communities.

Keywords: environmental assessment; transportation mode; retail distribution; sustainable customer transportation; logistics of retail channel; carbon label; carbon emission label

\section{Introduction}

An increasing number of supply chains are adopting carbon regulatory mechanisms to achieve sustainable development, such as introducing carbon labels on products to indicate the contribution to climate change made by the product throughout its lifespan [1,2]. Although the carbon dioxide emitted as a byproduct of the manufacture, transport, or disposal of a consumer product is listed on the carbon emission label, should the same products consumed in different retail channels have an identical carbon footprint? Worldwide, consumers buy one million plastic bottles every minute. By 2021, the number of plastic drink bottles produced globally is forecast to reach more than half a trillion [3]. Consumers in Taiwan use an estimated 4.5 billion plastic drink bottles annually. Excluding packaged water, the total packaged beverage sales in Taiwan in 2016 totaled $\$ 1860$ million USD, and brick-and-mortar store sales accounted for 86 percent of that market [4]. With more than 10,000 convenience stores (c-stores) covering a service area of 35,980 square kilometers and a population of 23 million, Taiwan has the highest c-store density per capita in the Asia-Pacific region [5]. The leading brand in the retail industry of Taiwan is 7-Eleven, with more than 5000 franchised c-stores. Ten million receipts are issued every day by 
7-Eleven stores, which means that more than half of Taiwan's population aged 15 or above shops in one every day. The location of a physical store is one of the important factors in determining the carbon footprint due to human transportation [6]. Most Taiwanese c-stores are placed in densely populated areas and do not have enough inventory space. Thus, they utilize the small quantity of frequently delivered goods to continuously provide the goods with the highest demand. In cities, these daily deliveries can generate excessive emissions and damage the environment. Although the large number of stores means economies of scale and logistics cost advantages for the parent company, urban areas are often exposed to large amounts of greenhouse gas (GHG) emission due to such frequent logistics activity.

A considerable amount of research has been undertaken to measure the effect of retail delivery networks on the environment. Wang, Zhuang, and Lin [7] discuss the environmental effects of replenishing packaged drinks to be sold in retail channels. Wang et al.'s study [7] presents a comparative life-cycle assessment (LCA) of two replenishment systemsone for a 7-Eleven c-stores and one for hypermarkets, as illustrated in Figure 1. UniPresident Enterprise Co., Ltd. (No. 301, Zhongzheng Rd., Yongkang Dist., Tainan City 710, Taiwan) is Taiwan's largest food production company. It also operates Starbucks, 7-Eleven, Mister Donut, and Carrefour. The supply of packaged drinks from the UniPresident production plant to the distribution centers (DCs) is called Phase I distribution. Phase II distribution is then from the DCs to the retail stores. Due to different truck capacities and transportation distances, researchers report that the impact indicators when distributing 1800 cartons of 10-ounce packaged beverages to the point of sale (POS) of Carrefour hypermarkets are lower than those of 7-Eleven c-stores, suggesting to consumers that the packaged beverages sold in Carrefour hypermarkets are thus more beneficial to the environment.

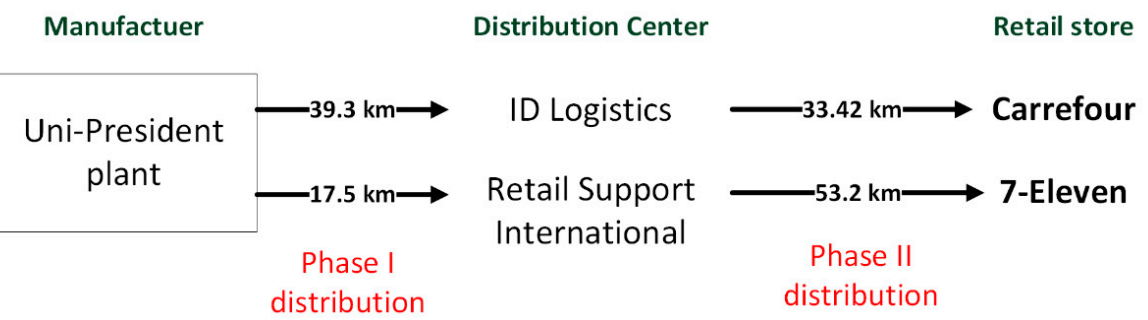

Figure 1. The two-phase distribution of packaged drinks from the producer to retail stores [7].

However, store location and density in these retail channels influences not only retailers' replenishment costs but also the modes of transportation used to travel to the stores of their consumers. Consumers have to travel a long way to shop with shops few and far between, but shopping journeys are shorter when there is a dense network of shops. We find that assessing the impact of distribution stages is necessary but insufficient to assess which channel system is more beneficial to the community; it is also necessary to include the environmental assessment of consumers' choice of transportation mode, as shown in Figure 2. In view of the rising demand from consumers for environmentally friendly goods and the understanding of issues related to sustainable growth, it is important to scientifically address the life-cycle environmental implications of drinking packaged beverages. Therefore, this study incorporated the impact of consumer preference of transportation mode from their residences to retail stores on the environment. The research utilized a streamlined LCA (SLCA) with background data available in the SimaPro 7 database [8,9]. The Eco-indicator 99 method [10], the most widely used endpoint impact assessment method in LCA, was adopted to assess and present the environmental assessment. 


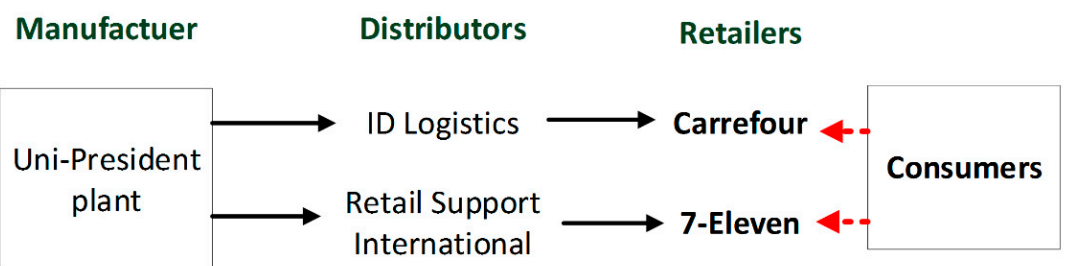

Figure 2. The distribution and consumption processes of packaged beverages [7].

The remainder of this paper is structured as follows. Section 2 reviews the impact assessment results of replenishing the two retail channels presented in Wang et al. [7], followed by an inventory of consumer transportation to these c-stores and the hypermarket channels in Taiwan. The impact assessment results from consuming the same functional unit (FU) in the two retail channels are presented in Section 4. The final section summarizes the results, explores their ramifications, and offers avenues for further analysis.

\section{Review of the Distribution Stage's Life-Cycle Inventory}

This section summarizes Wang et al.'s SLCA [7], along with the system boundaries and functional unit (FU). Their study illustrates the environmental assessment of two retail channel replenishment systems in Tainan city, where 770,000 people reside on 176 square kilometers of land. Figure 3 illustrates the sites of 217 7-Eleven and four Carrefour hypermarkets in Tainan City. Their LCA research evaluates the impacts of the distribution stages on the investigated beverage retail chains on the environment, which enables consumers to make an environmentally conscious choice as to which distribution channel holds the smallest environmental burden for packaged drinks to be sold.

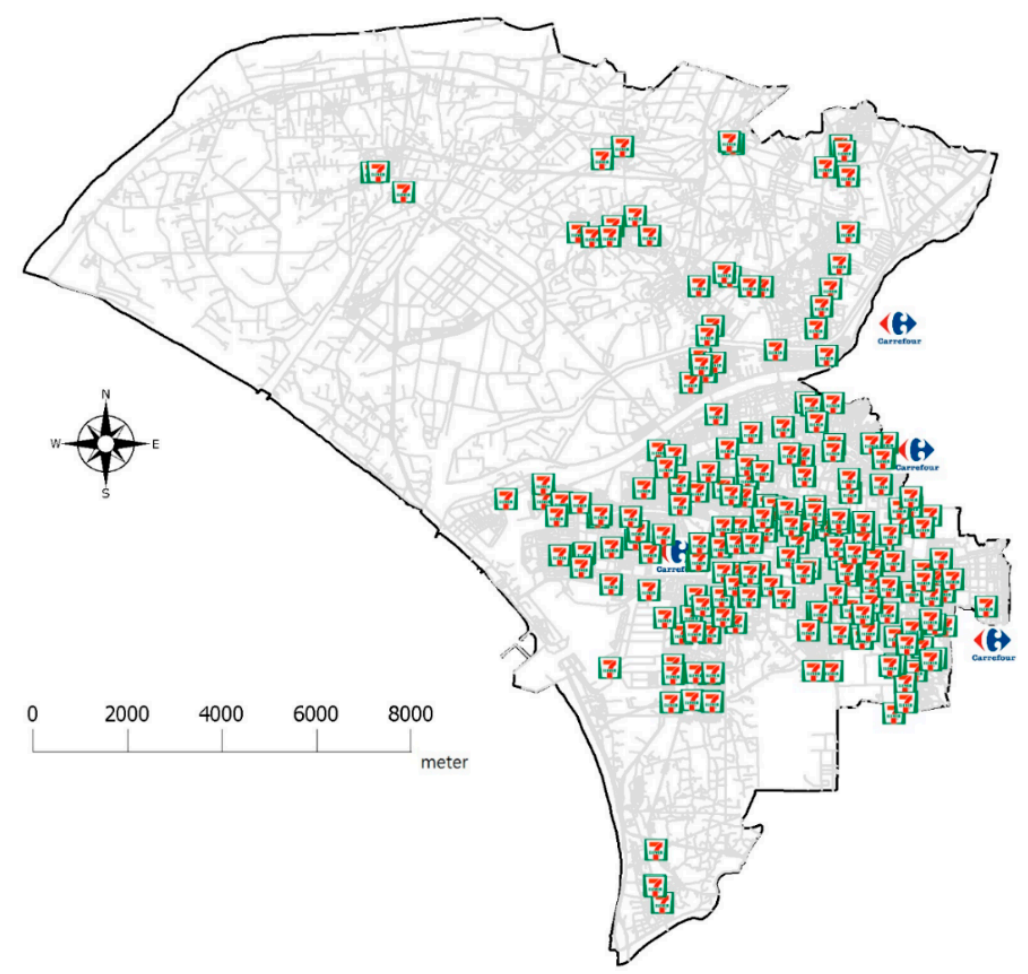

Figure 3. Carrefour's locations and 7-Eleven shops in Tainan City.

Wang et al.'s LCA study [7] is focused on practical input data for the packaged beverage replenishment systems of Uni-President Enterprise Co. According to Eco-indicator 99, the life-cycle impact assessment (LCIA) outcomes for the distribution of the FU to 217 7-Eleven and four Carrefour hypermarkets is shown in Figure 4. The figure presents a 
single-scoring life-cycle inventory assessment of deliveries to Carrefour/7-Eleven using a fully loaded truck and shows the contribution of each delivery phase to this assessment. In Phase I distribution, a 25-ton truck with 1800 beverage boxes is tasked with transporting the packed drinks to individual distribution centers from the production facility. Because the transportation distance of $39.9 \mathrm{~km}$ between the produce facility and ID Logistics (Carrefour's DC) is longer than the transport distance of $17.5 \mathrm{~km}$ between the production facility and the DC for 7-Eleven, Retail International Support, the 10.44-point $\mathrm{Pt}$ ) effect of the Carrefour distribution network is greater than the 4.58-point effect of the 7-Eleven distribution network. A matched-pair $t$-test demonstrates that the impact is significantly different at the 0.1 level, which indicates that there is a discrepancy between the environmental assessment of the producer's distribution to ID Logistics and that of the producer's distribution to Retail Support International for the same FU.

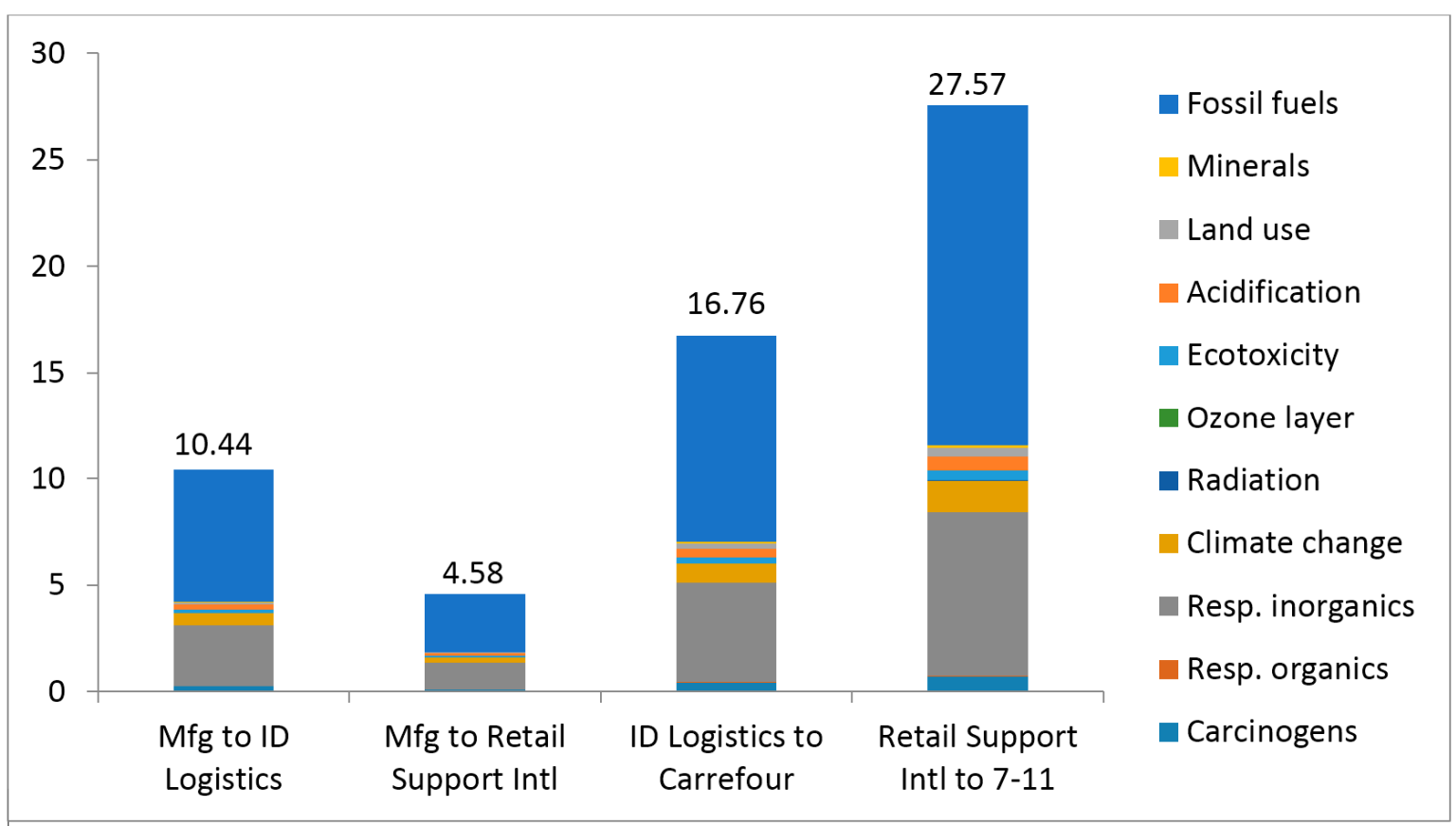

Figure 4. Summary of single score for life-cycle assessment (LCA) adopting the "Eco-indicator 99" impact assessment [7].

A 20.5-ton truck filled with 1800 boxes of drinks is tasked with replenishing packaged drinks from the DC to Carrefour hypermarkets in Phase II delivery (from DC to hypermarket units), while a 10.5-ton truck is allocated to transport packaged drinks from the DC to 7-Eleven c-stores. Because the transportation distance of $33.42 \mathrm{~km}$ between the DC and Carrefour hypermarkets is shorter than the transport distance of $53.2 \mathrm{~km}$ between the DC (Retail International Support) and 7-Eleven, the 16.67-point effect of the Carrefour distribution network is less than that of the 27.57-point effect of 7-Eleven distribution networks. A matched-pair $t$-test demonstrates that the impact is significantly different at the 0.1 level, which indicates that there is a discrepancy between the environmental assessment of the Retail Support International's distribution to 7-Eleven c-stores and those from ID Logistics to Carrefour hypermarkets for the same FU. In total, the 27.20-point impact of distributing to Carrefour hypermarkets is less than that of the 32.05-point effect of distributing to 7-Eleven c-stores.

In Phase I distribution, delivering from the producer to the DC for Carrefour has a higher effect than delivering from the producer to the DC for 7-Eleven c-stores. In Phase II distribution, delivering from the DC for Carrefour to Carrefour hypermarkets has a lower effect than delivering from the DC for 7-Eleven c-stores to the 7-Eleven c-stores. Traveling from the production plant to the DC for 7-Eleven has a lower (better) effect during Phase I delivery than traveling from the production plant to the DC for Carrefour. 
In Phase II delivery, there is a greater (worse) effect on traveling from the DC for 7-Eleven than delivering from the DC for Carrefour to Carrefour hypermarkets. In total, in the distribution stage, the impact indicators for the 1800 cartons of drinks in 7-Eleven c-stores are greater than for those in Carrefour hypermarkets. The delivery distance is the critical element causing this result.

\section{Life-Cycle Inventory of Consumption}

The research extends the work of Wang et al. [7] and presents a comparative SLCA for consuming the same FU in the two retail channels-c-stores and hypermarkets. This study focused on one brand of packaged beverage consumed in these two channels and refilled through various replenishment systems to compare the environmental assessment of consumption of packaged drinks in 7-Eleven c-stores against that in Carrefour hypermarkets. Impact assessments depending on the inputs and outputs of distribution and consumer shopping transportation were used to determine which retail channel is more environmentally friendly while omitting the phases of raw material procurement, commodity production process, and usage and disposal stages. The inventory analysis portion primarily describes the emission during the distribution process and consumer transportation.

\subsection{Goal Definition and Scope}

The study used the LCA approach to quantify the environmental impact of consuming packaged beverages in retail channels. This study was centered on the packaged beverage retail supply chain, which includes the replenishment process and customers transportation to 7-Eleven c-stores or Carrefour hypermarkets. There are three important components of the LCA: life-cycle inventory (LCI), LCIA, and improvement assessment. The LCA in this study was streamlined by (1) limiting the number of resources, pollutants, and environmental assessment of the distribution and consumption stages and (2) adjusting the system boundary and limiting the life-cycle of packaged beverages to transportation and consumption (as shown in Figure 5). It can be a time-consuming and costly process to perform a comprehensive full-scale LCA; it is therefore always more convenient to use a simpler form. Generally, simpler approaches are known as streamlined LCAs (SLCAs). The material acquisition processes, production, usage, and disposal were omitted as their environmental assessment is identical, irrespective of whether the packaged drinks are consumed in 7-Eleven c-stores or Carrefour hypermarkets. Due to the composition of distribution channels and customer choice of transportation mode, distribution and consumption phases have been described as causing different environmental impacts. The main objective of this analysis was to provide the quantitative environmental footprint of the focal product, particularly in the phases of distribution and consumption, and prioritize beneficial improvements for customer choice of transportation mode.

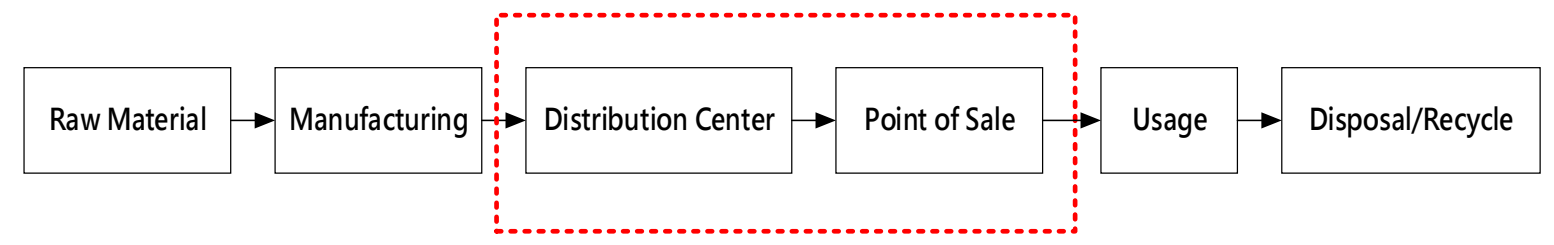

Figure 5. The system boundaries for the life-cycle of replenishment and sales of packaged drinks.

\subsection{Input Inventory Analysis of Consuming Packaged Drinks}

The collection of LCI input data on the consumption of packaged drinks for sales in brick-and-mortar retail stores is defined in this section. These input data of the inventory include the consumption frequency and quantity, consumer transport mode, and primary traveling distance. The inventory data are measured on the basis of FU mass. Table 1 lists the average transportation distance and consumption quantity per visit for shopping in each channel. According to the average grocery expenditure and the buying behavior of 
consumers at hypermarkets and c-stores [11], we set the average consumption quantity of packaged beverages at two cartons and two packs in Carrefour and 7-Eleven, respectively. Therefore, it would take 900 and 21,600 visits in Carrefour and 7-Eleven, respectively, to consume the 1800 cartons of 6-ounce packaged beverages.

According to traffic surveys conducted on 20 main intersections in Tainan City, the average speed is $33.43 \mathrm{~km}$ per hour [12]. The average time that a consumer takes to travel to a local hypermarket is $20.2 \mathrm{~min}$ [13]. Thus, a car traveling at the average speed of $33.43 \mathrm{~km}$ per hour will travel an average driving distance of $11.25 \mathrm{~km}$. To account for the environmental assessment at the consumption phase, an assumption of average distance traveled from a consumer' residence to a 7-Eleven c-store was made. Based on the information provided by regional store expansion consultants and an investigation into the guidelines of a new store's establishment for 7-Eleven c-stores [13,14], the average distance between a person's residence and a c-store is $300 \mathrm{~m}$. This statistic is broadly consistent with most Taiwanese consumers, who will walk to a c-store within five minutes of their home.

Table 1. Average transportation distance vs. consumption quantity per purchase.

\begin{tabular}{cccc}
\hline To & Quantity & Shopping Visit & Distance \\
\hline Carrefour & 2 cartons & 900 & $11.25 \mathrm{~km}$ \\
7-Eleven & 2 packs & 21,600 & $0.3 \mathrm{~km}$ \\
\hline
\end{tabular}

Based on surveys of the most dominant modes of urban transport for hypermarket consumers [15], private cars account for $60.4 \%$ of transport, followed by buses (3.2\%), scooters (29.4\%), and walking (4.2\%). Wang et al. [16] distributed 450 questionnaires to out-of-town students from two universities. These survey results indicate that the breakdown of transportation modes used by college students to the nearest c-store is: walking $(74.14 \%)$, scooter $(24.83 \%)$, automobile $(0.25 \%)$, and bicycle $(0.74 \%)$. Figure 6 indicates the replenishment process from the producer to the Carrefour hypermarkets and the modes of transportation consumers use to get to those Carrefour hypermarkets. Carrefour hypermarkets are not easily accessible except by car or scooter. Figure 7 indicates the replenishment process from the producer to the 7-Eleven c-stores and the modes of transportation consumers use to get to those 7-Eleven c-stores. The LCI input data for frequency of consumer transportation modes to retail stores during the consumption of 1800 cartons of 24 pack/10 oz. beverages, the cause of environmental concerns, are summarized in Table 2.

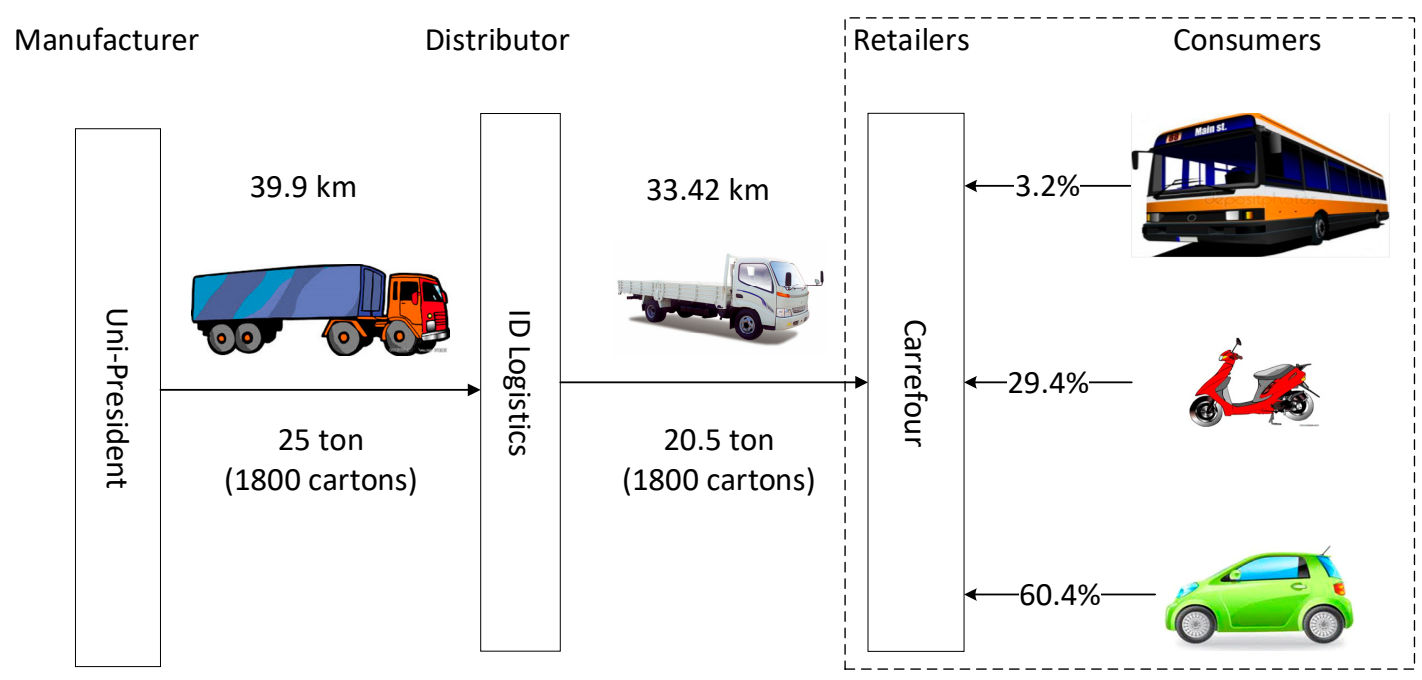

Figure 6. The percentage of transportation modes consumers used to travel to the Carrefour hypermarkets. 


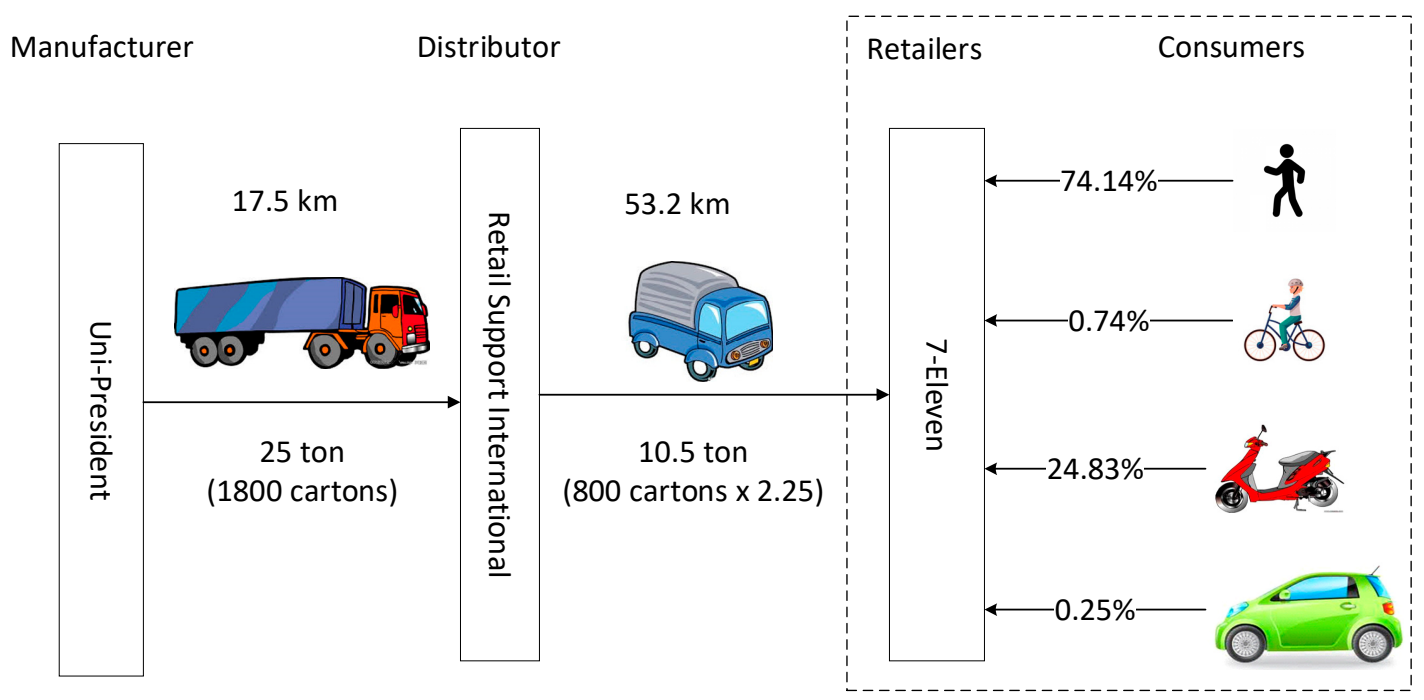

Figure 7. The percentage of transportation modes consumers used to travel to the 7-Eleven c-stores.

Table 2. Input data of LCI for consuming 1800 boxes in shopping visits.

\begin{tabular}{ccc}
\hline To & Transportation Mode & Shopping Visit \\
\hline \multirow{2}{*}{ Carrefour hypermarkets (900 visits) } & Car $(60.4 \%)$ & 543.6 \\
\cline { 2 - 3 } & Scooter $(29.4 \%)$ & 264.6 \\
\hline \multirow{2}{*}{ 7-Eleven c-stores (21,600 visits) } & Bus $(3.2 \%)$ & 28.8 \\
\hline
\end{tabular}

\section{Life-Cycle Impact Assessment}

The environmental assessment of 1800 boxes of 24 pack/10 oz. drinks consumed in Carrefour hypermarkets and 7-Eleven c-stores in Tainan City is presented in this section, based on the endpoint LCIA method of Eco-indicator 99, implemented in Ecoinvent Data v2.0.

\subsection{Eco-Indicator 99}

The LCIA outcomes are shown here for the consumption of the FU in 7-Eleven c-stores and Carrefour hypermarkets based on the Eco-indicator 99 approach. Table 3 lists the normalized and weighted LCA results based on transportation mode, using the Ecoindicator 99 method of impact assessment. A summary of the normalized and weighted single score results is presented in Figure 8. During the consumption of 1800 cartons of 6-ounce packaged beverages, the impact caused by consumer transport to Carrefour hypermarkets $(14.10 \mathrm{Pt})$ was lower than that for 7-Eleven c-stores $(62.83 \mathrm{Pt})$. Figure 8 presents the single score life-cycle inventory assessment for consumer transport to 7-Eleven c-stores/Carrefour hypermarkets and displays the contribution of individual transport modes at the consumption stage. 
Table 3. SimaPro Output. A hierarchical perspective was used to normalize and weight the LCI results.

\begin{tabular}{cccccc}
\hline \multirow{2}{*}{ Impact Category } & \multicolumn{3}{c}{ To Carrefour } & \multicolumn{2}{c}{ To 7-Eleven } \\
\cline { 2 - 6 } & By Car & By Scooter & By Bus & By Car & By Scooter \\
\hline Carcinogens & 0.437 & 0.072 & 0.0055 & 0.0434 & 1.46 \\
Respiratory organics & 0.00942 & 0.034 & 0.000188 & 0.000936 & 0.688 \\
Respiratory inorganics & 1.62 & 0.511 & 0.126 & 0.161 & 10.4 \\
Climate change & 0.712 & 0.229 & 0.0215 & 0.0707 & 4.63 \\
Radiation & 0.0145 & 0.000834 & 0.000206 & 0.00144 & 0.0169 \\
Ozone layer & 0.00468 & 0.000133 & 0.0000181 & 0.0000465 & 0.0027 \\
Ecotoxicity & 0.162 & 0.0449 & 0.00466 & 0.0161 & 0.909 \\
Acidification & 0.121 & 0.0346 & 0.0119 & 0.0121 & 0.701 \\
Land use & 0.242 & 0.0165 & 0.00276 & 0.0241 & 0.335 \\
Minerals & 0.094 & 0.021 & 0.00199 & 0.00934 & 0.426 \\
Fossil fuels & 7.24 & 2.08 & 0.233 & 0.73 & 42.2 \\
Total & 10.660 & 3.040 & 0.410 & 1.060 & 61.770 \\
\hline
\end{tabular}

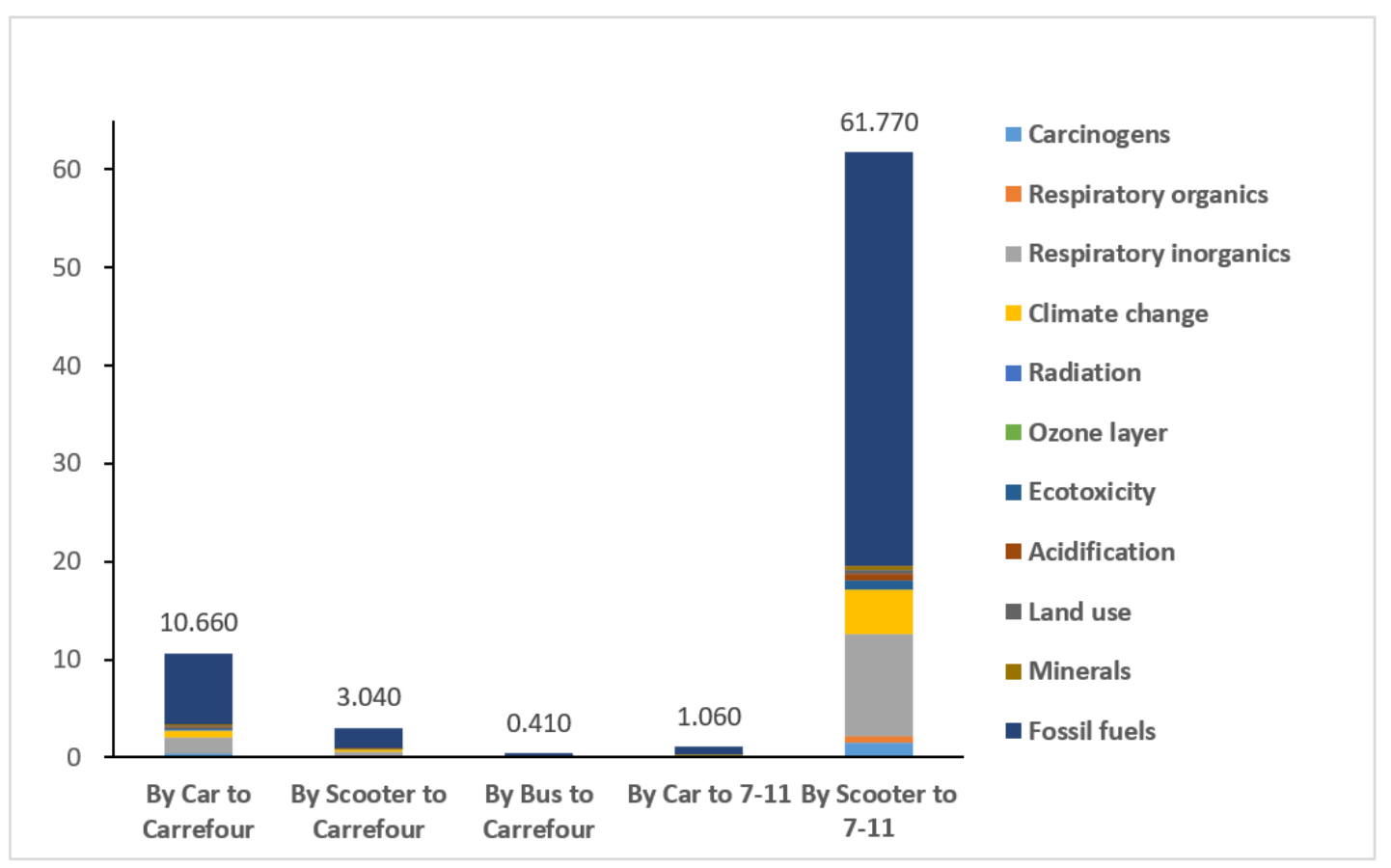

Figure 8. Environmental assessment of FU consumption in Carrefour hypermarkets and 7-Eleven c-stores according to transportation mode.

According to Wang et al. [7], there is a distinction between the environmental assessment of the distribution to the DC for Carrefour from the production plant and that of the distribution to the DC for 7-Eleven c-stores from the production plant for the same FU. The environmental impact of distributing to Carrefour hypermarkets $(27.20 \mathrm{Pt})$ is lower than that of distributing to 7-Eleven c-stores $(32.15 \mathrm{Pt})$. Table 4 lists the normalized and weighted LCA results for these distribution and consumption stages. The paired $t$-test (in Table 5) shows that the single score for 1800 cartons of 24 pack $/ 10 \mathrm{oz}$. beverages consumed in 7-Eleven c-stores and Carrefour hypermarkets differs at a significance level of 0.1 . Figure 9 presents the summary of the normalized and weighted single score results. The impact of the same FU sold in 7-Eleven c-stores at $94.98 \mathrm{Pt}$ is higher than that sold in the Carrefour hypermarkets at $41.30 \mathrm{Pt}$. Figure 10 presents the sum of the single score life-cycle inventory assessment of distribution to these locations and consumer transport to Carrefour/7-Eleven. 
Table 4. The impact assessment of 1800 cartons consumed at the POS of Carrefour and 7-Eleven.

\begin{tabular}{lllll}
\hline \multirow{2}{*}{ Impact Category } & \multicolumn{2}{c}{ Distribution Phase } & \multicolumn{2}{c}{ Consumption Phase } \\
\cline { 2 - 5 } & \multicolumn{1}{c}{ To Carrefour } & To 7-Eleven & To Carrefour & To 7-Eleven \\
\hline Carcinogens & 0.7 & 0.841 & 0.51 & 1.50 \\
Respiratory organics & 0.0129 & 0.0159 & 0.04 & 0.69 \\
Respiratory inorganics & 7.53 & 8.95 & 2.26 & 10.56 \\
Climate change & 1.44 & 1.701 & 0.96 & 4.70 \\
Radiation & 0.0191 & 0.0254 & 0.02 & 0.02 \\
Ozone layer & 0.00114 & 0.00134 & 0.00 & 0.00 \\
Ecotoxicity & 0.445 & 0.5392 & 0.21 & 0.93 \\
Acidification & 0.659 & 0.77 & 0.17 & 0.71 \\
Land use & 0.3193 & 0.4245 & 0.26 & 0.36 \\
Minerals & 0.1387 & 0.1605 & 0.12 & 0.44 \\
Fossil fuels & 15.93 & 18.72 & 9.55 & 42.92 \\
\hline Total & 27.20 & 32.15 & 14.10 & 62.83 \\
\hline
\end{tabular}

Table 5. The paired $t$-test of Carrefour and 7-Eleven.

\begin{tabular}{lll}
\hline & Carrefour & 7-Eleven \\
\hline Mean & 3.754104 & 8.63444 \\
Variance & 59.87955 & 341.2319 \\
Observations & 11 & 11 \\
Pearson Correlation & 0.997642 & \\
Hypothesized Mean Difference & 0 & \\
df & 10 & \\
$\mathrm{t}-$ Stat & -1.50351 & \\
$\mathrm{P}(\mathrm{T} \leq \mathrm{t})$ & 0.081807 & \\
\hline
\end{tabular}

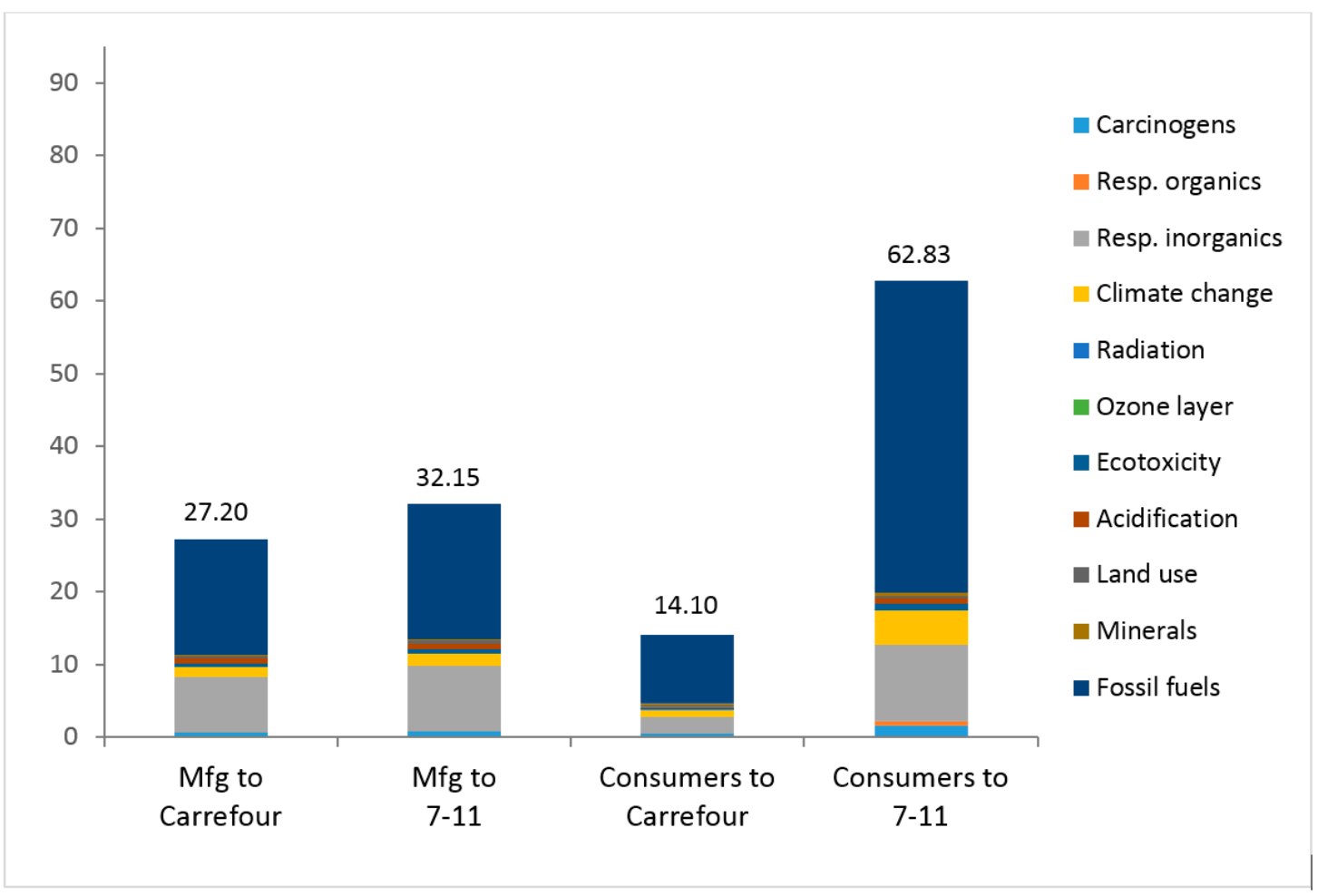

Figure 9. Single score summary of LCA for distributing the FU. 


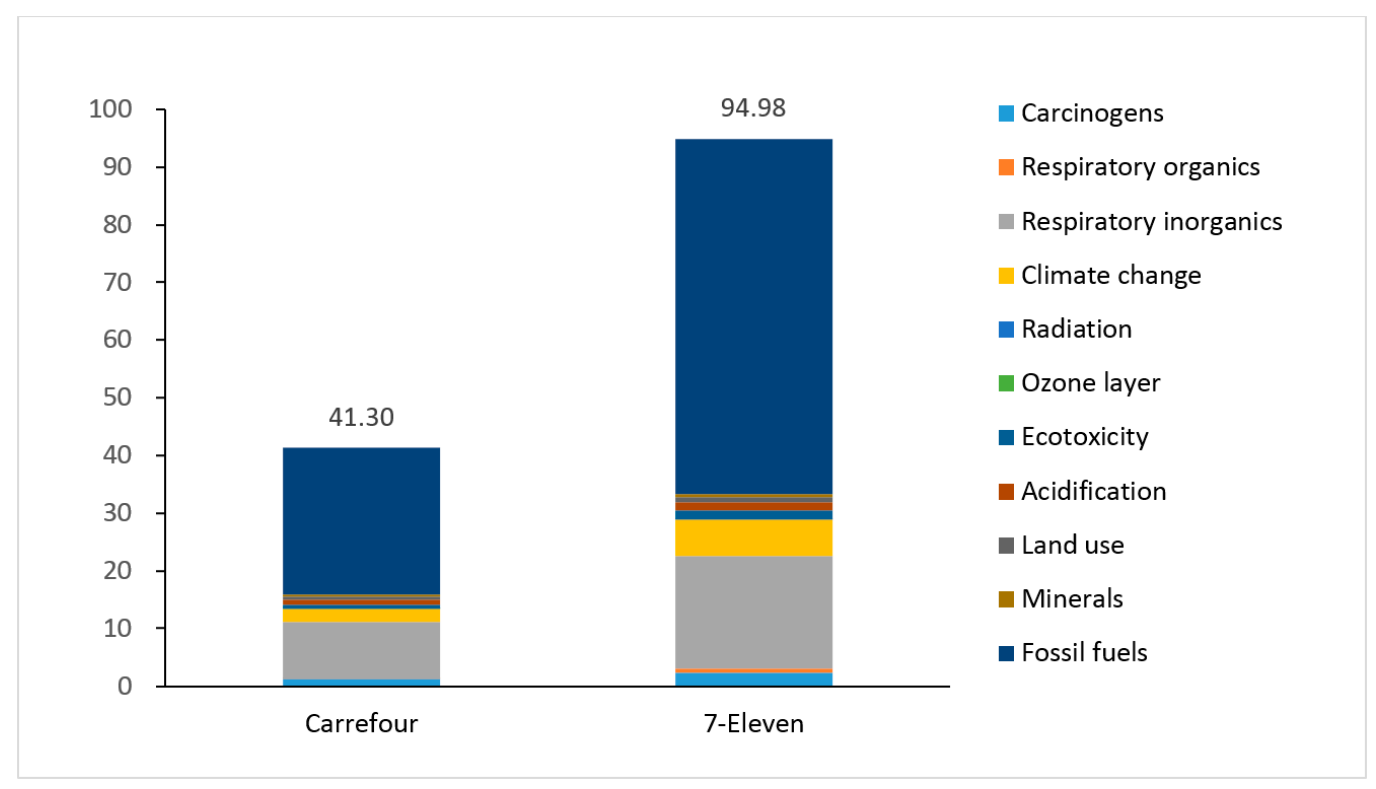

Figure 10. Comparative analysis of consuming 1800 cartons of packaged beverage in Carrefour and 7-Eleven (SimaPro, Eco-indicator 99).

\subsection{Improvement Assessment}

The Eco-indicator of the consumption stage of 1800 cartons of 24 pack $/ 10 \mathrm{oz}$. beverages defines the consumption-level footprint. This research estimates that the single score for 1800 cartons of 24 pack/10 oz. beverages consumed in 7-Eleven c-stores and Carrefour hypermarkets differs at a significance level of 0.1. The impact assessment for the FU consumed in Carrefour hypermarkets is lower than that for 7-Eleven c-stores, the difference mostly contributed by fossil-fuel scooters. According to the breakdown of transportation modes, $24.83 \%$ of college students ride scooters to the nearest c-store. Figure 11 therefore highlights the single score life-cycle inventory assessment for traveling from consumers' residences to 7-Eleven c-stores using fossil-fuel scooters. Consumption of fossil fuels is the biggest impact, followed by inorganic respiratory products, climate change, and carcinogens. Consumers should accept alternative-fuel vehicles such as electric motorcycles or scooters to replace the current fossil-fuel scooters. Reducing the use of fossil-fuel scooters between residences and 7-Eleven c-stores will minimize the harm to the environment effectively.

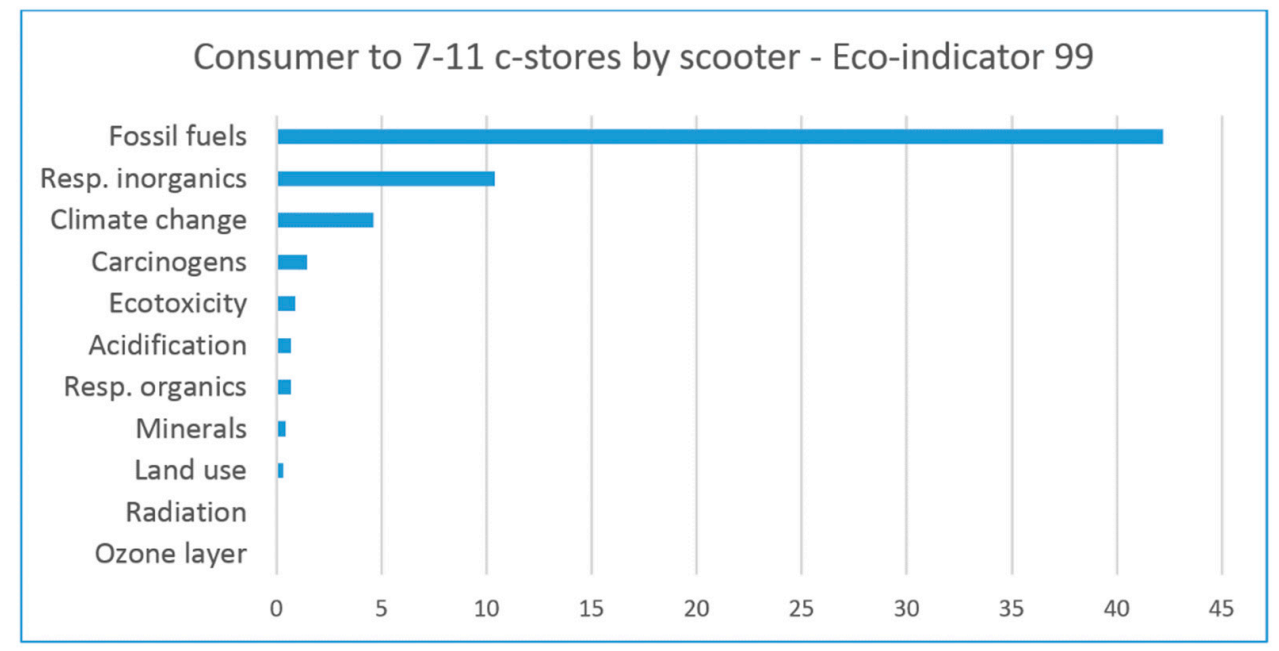

Figure 11. Environmental assessment of FU consumption through travel to 7-Eleven c-stores by fossil-fuel scooters. 


\section{Conclusions}

The focus of this research was on the retail supply chain of packaged drinks, which includes the inbound replenishments to stores. It centered on the last segment between retail stores and customer residences. The study extended Wang et al.'s effort [7] to improve the understanding of the environmental assessment of consuming in the two major retail chains, 7-Eleven c-stores and Carrefour hypermarkets. The study was conducted with a POS-level LCA through the use of SimaPro. The software was used to measure possible environmental harm depending on the customer's choice of transport mode and to evaluate the impacts of the two retail chains. The transportation-focused LCA excluded the acquisition of raw material, production, use, and disposal phases. It was performed by first aggregating relevant LCI data from published reports and commercial databases. An analysis of the overall environmental assessment of inputs and carbon emissions at the point of purchase was undertaken, with the intention of giving priority to the mode of transportation chosen by consumers.

This report presents the results of an environmental LCA of beverage retail channels of 7-Eleven c-stores and Carrefour hypermarkets. The LCA was conducted in compliance with the ISO 14040 series guidelines [17]. The FU for consuming 1800 boxes of 24 pack/10 oz. drinks in 7-Eleven c-stores and Carrefour hypermarkets was modeled in Tainan City. The boundary of the consumer system contains the inputs and outputs of the modes of transportation consumers used to travel to retail stores, transportation distance, and shopping frequency. The LCA was first carried out by collecting the related LCI data from published papers and databases that are publicly available. The LCA software tool SimaPro was then used to perform a life-cycle impact assessment. Using Eco-indicator methods, the data showed that the main impacts were in the categories of fossil fuels, respiratory inorganics, and climate change.

Carrefour hypermarkets in the case study are not easily accessible except by car or scooter. When customers can reach a store easily by mass transit or alternative transportation, such as walking, biking, or carpooling, the environmental impact of customer transportation can be reduced. Taiwan is the world's second most densely populated area, with 23 million people squeezing into 35,800 square kilometers of land, two-thirds of which is rugged mountains. Moreover, Taiwan has 32.2 motor vehicles per 100 people and 15.09 million scooters, or 67.6 motorized vehicles for every 100 people. Taiwan has 419.3 scooters per square kilometer in terms of area, whereas Singapore and Japan have 210 and 33.5, respectively. Therefore, reducing the use of fossil-fuel scooters between residences and 7-Eleven c-stores may effectively reduce the environmental damage. Consumers should accept electric vehicles with emerging technology and innovations to replace the fossil-fuel vehicles they currently use.

This study systematically outlines the potential environmental assessment of packaged drinks consumed in two retail channels in Taiwan. It will assist customers in finding new areas of change. Without unduly compromising the clarity of the underlying assumptions and data sources, the analysis attempted to communicate knowledge in an easily accessible way. This research is also targeted at non-LCA experts and therefore focuses on a general analysis of the retailing systems and their environmental profiles instead of recording the entire LCA methodology and measurement process that produced the findings. The aim was to clarify the argument for sustainable consumer transport for the environment and industry and to suggest new policies and pollution reduction goals associated with increasing the use of sustainable transport.

Author Contributions: Conceptualization, J.W. and P.-C.L.; methodology, P.-C.L.; software, P.-C.L.; validation, J.W.; investigation, P.-C.L.; resources, P.-C.L.; writing-original draft preparation, P.-C.L.; writing-review and editing, J.W.; funding acquisition, J.W. and P.-C.L. Both authors have read and agreed to the published version of the manuscript.

Funding: This research was funded by the Ministry of Science and Technology, R.O.C., grant number 104-2410-H-006-080. 
Institutional Review Board Statement: Not applicable.

Informed Consent Statement: Not applicable.

Conflicts of Interest: The authors declare no conflict of interest.

\section{References}

1. Liang, T.-C.; Situmorang, R.O.P.; Liao, M.-C.; Chang, S.-C. The relationship of perceived consumer effectiveness, subjective knowledge, and purchase intention on carbon label products-A case study of carbon-labeled packaged tea products in Taiwan. Sustainability 2020, 12, 7892. [CrossRef]

2. Meyerding, S.; Schaffmann, A.; Lehberger, M. Consumer preferences for different designs of carbon footprint labelling on tomatoes in Germany-does design matter? Sustainability 2019, 11, 1587. [CrossRef]

3. The Guardian. A Million Bottles a Minute: World's Plastic Binge 'as Dangerous as Climate Change'. Available online: https:/ / www.theguardian.com/environment/2017/jun/28/a-million-a-minute-worlds-plastic-bottle-binge-as-dangerousas-climate-change?CMP=share_btn_link (accessed on 24 April 2018).

4. $\quad$ ITIS. 2016 Taiwan Food Industry Report; ITIS Project; Food Industry Research \& Development Institute: Hsinchu, Taiwan, 2017. (In Chinese)

5. Yun, M. Convenience stores become one-stop shop in Taiwan. YAHOO! News, 29 January 2017.

6. Willoughby, S. WWF Sustainable Customer Transportation. An Opportunities Guide for Retailers and Shopping Centers. Available online: http:/ /awsassets.panda.org/downloads/wwfikea_stop_1.pdf (accessed on 24 April 2018).

7. Wang, J.; Zhang, H.-H.; Lin, P.-C. The environmental impact of distribution to retail channels: A case study on packaged beverages. Transp. Res. Part D Transp. Environ. 2016, 43, 17-27. [CrossRef]

8. SimaPro 7.3; ecoinvent data v2.0 edn; PRé Consultants: Amersfoort, The Netherlands, 2012.

9. Wang, J.; Hou, C.-C.; Lin, P.-C. Two-phase assessment for the environmental impacts from offset lithographic printing on color-box packaging. J. Clean. Prod. 2013, 53, 129-137. [CrossRef]

10. Goedkoop, M.J. The Eco-Indicator 99 a Damage Oriented Method for Life Cycle Impact Assessment Methodology Report; PRé Consultants: Utrecht, The Netherlands, 1999.

11. Lin, P.-C.; Lin, C.-J.; Shen, C.-W.; Wang, J. The revenue and logistics costs of convenience store chains in Taiwan. Int. J. Logist. Res. Appl. 2019, 48, 1255-1273. [CrossRef]

12. Tainan City Government. Tainan City Road Traffic Characteristics Analysis Commission Plan. 2016. Available online: http: / / traffic.tainan.gov.tw/FileDownLoad/FileUpload/20150828141127454528.pdf (accessed on 24 April 2018).

13. Chen, I.-C. Research on Traffic Impact of Warehouse-Typed Hypermarket Stores-Trip Occurrence and Parking Demand; Institute of Transportation, Ministry of Transportation and Communications: Zhongzheng, Taiwan, 1998. Available online: https: // www.motc.gov.tw/ch/home.jsp?id=1679\&parentpath=0,6\&mcustomize=statistics105.jsp (accessed on 31 December 2020). (In Chinese)

14. Lin, P.-C.; (National Taiwan University, Taipei, Taiwan); Huang, W.-W.; (National Taiwan University, Taipei, Taiwan). UnitPresident Enterprise, Expert Interviews. Personal communication, 2012.

15. Lin, Y.-T. The Study of Consumer Behavior in Metropolis Convenience Chain Stores. Master's Thesis, Fu Jen Catholic University, New Taipei City, Taiwan, 2006. Available online: https: / ndltd.ncl.edu.tw/cgi-bin/gs32/gsweb.cgi?o=dnclcdr\&s=id=\%22094 FJU00720008\%22.\&searchmode=basic (accessed on 31 December 2020). (In Chinese)

16. Wang, H.-P.; Lin, C.-H.; Lin, P.-M.; Lee, Y.-T.; Shin, P.L.; Jhuang, C.-Y. A study on factors of college students' off-campus housing decision. Provid. Stud. Humanit. Soc. Sci. 2010, 42, 143-164.

17. ISO. Environmental Management_Life Cycle Assessment_-Principles and Framework; ISO 14040; International Organisation for Standardisation (ISO): Geneva, Switzerland, 2006. 